\title{
Petunjuk bagi Penulis
}

Silakan membaca pedoman penulisan AgriHealth: Journal of Agri-food, Nutrition and Public Health, dan harap mengikuti instruksi ini dengan seksama. Naskah yang tidak mematuhi instruksi akan dikembalikan untuk revisi tanpa ulasan. Pemimpin Redaksi berhak untuk mengembalikan naskah yang tidak disiapkan sesuai dengan pedoman penulisan ini.

Penulis harus mengirimkan artikel secara online melalui website: https://jurnal.uns.ac.id/agrihealth/about/submissions\#onlineSubmissions

AgriHealth: Journal of Agri-food, Nutrition and Public Health, diterbitkan oleh Pusat Penelitian dan Pengembangan Pangan, Gizi dan Kesehatan Masyarakat (P4GKM) Lembaga Penelitian dan Pengabdian kepada Masyarakat (LPPM) UNS, merupakan jurnal yang memuat artikel ilmiah hasil kajian penerapan ilmu pengetahuan dan teknologi kepada para pemangku kepentingan (stakeholder) di bidang pertanian ramah lingkungan, pangan, gizi dan kesehatan masyarakat. Jurnal ini juga menerima makalah tentang topik terkait lainnya sepanjang topik tersebut termasuk dalam konteks lingkup multi-disiplin yang lebih luas dari Pertanian, Gizi, Kebidanan dan Kesehatan Masyarakat.

Format Naskah

1. Naskah ditulis dalam 11 poin Times New Roman font 1,5 spasi di kertas A4. Margin di keempat sisi adalah 2,5 cm.

2. Format file pengolah kata berikut dapat diterima untuk dokumen manuskrip utama untuk semua: Microsoft Word (DOC, DOCX) dan format teks kaya (RTF) dengan ukuran tidak lebih dari 3MB.

3. Format berikut untuk file gambar: Pastikan file karya seni dalam format yang dapat diterima (TIFF, EPS atau file MS Office) dan dengan resolusi yang benar. Pastikan setiap ilustrasi memiliki judul. Teks keterangan disediakan secara terpisah, tidak dilampirkan pada gambar. Keterangan harus terdiri dari judul singkat (bukan pada gambar itu sendiri) dan deskripsi ilustrasi. Simpan teks dalam ilustrasi itu sendiri seminimal mungkin, tetapi jelaskan semua simbol dan singkatan yang digunakan. Beberapa angka dapat dinyatakan sebagai satu angka (mis. 1a, 1b, 1c dll ...), sambil tetap mempertahankan batas maksimum 6 .

4. Teks harus dalam format satu kolom. Jaga tata letak teks sesederhana mungkin. Sebagian besar kode pemformatan akan dihapus dan diganti saat memproses artikel.

5. Nomor halaman terletak di kanan atas. 
6. Gambar dan Tabel ditempatkan dalam naskah (terintegrasi dengan naskah utuh).

Bagian naskah ditulis dalam urutan sebagai berikut :

JUDUL

ABSTRAK

PENGANTAR

BAHAN DAN METODE

HASIL DAN PEMBAHASAN

KESIMPULAN

UCAPAN TERIMA KASIH (Jika ada)

DAFTAR PUSTAKA

\title{
JUDUL
}

Judul ditulis dalam Bahasa Indonesia, Times New Roman 12pt, Bold

\begin{abstract}
Abstrak
Abstrak ditulis dalam Bahasa Indonesia dan Bahasa Inggris menggunakan huruf Times New Roman 11pt, spasi 1, dengan panjang teks antara 150-250 kata. Abstrak versi Bahasa Indonesia ditulis menggunakan Bahasa Indonesia baku dengan ejaan yang disempurnakan. Abstrak memaparkan secara ringkas tentang latar belakang, tujuan, metode pelaksanaan, hasil dan kesimpulan.
\end{abstract}

Kata kunci: berurutan sesuai abjad, terdiri dari 3-5 kata

\section{TITLE}

English, Times New Roman 12pt, Bold, Italic

\begin{abstract}
Abstrak versi Bahasa Inggris ditulis menggunakan Bahasa Inggris dalam bentuk past tense. Abstrak ditulis menggunakan huruf Times New Roman 11pt, spasi 1, Italic, dengan panjang teks antara 150-250 kata. Abstrak memaparkan secara ringkas tentang latar belakang, tujuan, metode pelaksanaan, hasil dan kesimpulan.
\end{abstract}

Keywords: berurutan sesuai abjad, Italic, terdiri dari 3-5 kata

\section{PENDAHULUAN}

Pendahuluan ditulis dengan huruf Times New Roman 11pt, Spasi 1,5. Pendahuluan memuat tentang latar belakang, masalah, rencana pemecahan masalah dan tujuan kegiatan yang dilaksanakan. Pendahuluan harus menyampaikan bahwa isi naskah dalam rangka mendukung penerapan ilmu pengetahuan dan teknologi kepada para pemangku kepentingan (stakeholder) di salah satu atau beberapa bidang pertanian ramah lingkungan, pangan, gizi 
dan kesehatan masyarakat. Tujuan kegiatan mengandung indikator-indikator keberhasilan kegiatan yang dapat diukur. Naskah dipaparkan secara naratif (tanpa penomoran di depan sub judul) dan pemaparan dalam bentuk sub judul dihindari. Jumlah kata pendahuluan tidak lebih dari 1.000 kata.

\section{BAHAN DAN METODE}

Bahan dan Metode ditulis dengan huruf Times New Roman 11pt, Spasi 1,5. Metode memaparkan secara rinci tentang jenis/rancangan kegiatan yang dilaksanakan, tempat dan waktu pelaksanaan, metode serta langkah-langkah pelaksanaan, pengukuran indikator keberhasilan sampai dengan monitoring dan evaluasi pelaksanaan kegiatan. Jumlah kata bahan dan metode tidak lebih dari 500 kata.

\section{HASIL DAN PEMBAHASAN}

Hasil dan Pembahasan ditulis dengan huruf Times New Roman 11pt, Spasi 1,5. Menjelaskan dan menguraikan tentang:

1. Realisasi pelaksanaan sesuai metode kegiatan (kaji terap, sosialisasi, pelatihan, mediasi dan konsultasi, pendidikan, advokasi dan lainnya)

2. Dokumentasi yang relevan dengan fokus utama kegiatan antara lain foto, tabel, grafik, bagan, gambar dan sebagainya. Setiap dokumentasi harus "dipanggil" dalam teks dan diberi pembahasan yang menjelaskan tentang produk atau kegiatan yang dilakukan

3. Analisis pencapaian indikator keberhasilan sesuai dengan tujuan kegiatan

4. Monitoring dan evaluasi pelaksanaan kegiatan, dapat berupa narasi kekuatan, kelemahan, peluang dan ancaman.

Dokumentasi harus dijamin dapat dicetak dengan jelas, resolusi dan ukuran garis (grafik) harus yakin tercetak jelas.

Tabel dibuat dengan lebar garis 1 pt dan tables caption (keterangan tabel) diletakkan di atas tabel. Keterangan tabel yang terdiri lebih dari 2 baris ditulis menggunakan spasi 1. Garis-garis tabel diutamakan garis horizontal saja sedangkan garis vertikal dihilangkan. Setiap tabel harus "dipanggil" dalam teks dan diberi pembahasan yang menjelaskan tentang isi tabel.

Jumlah kata hasil dan pembahasan tidak lebih dari 2.000 kata.

\section{KESIMPULAN}

Kesimpulan ditulis dengan huruf Times New Roman 11pt, Spasi 1,5. Berisi simpulan pelaksanaan kegiatan dan pencapaian indikator keberhasilan sesuai tujuan kegiatan. Saran (jika ada) dibuat berdasarkan implikasi dari simpulan. Jumlah kata kesimpulan tidak lebih dari 100 kata. 


\section{UCAPAN TERIMA KASIH}

Ucapan Terima Kasih ditulis dengan huruf Times New Roman 11pt, Spasi 1,5. Penulis menyampaikan terima kasih kepada pemberi dana kegiatan (jika terdapat nomor kontrak dapat dicantumkan dan tahun perolehan). Ucapan terima kasih juga dapat ditujukan kepada pihak-pihak yang berperan penting dalam pelaksanaan kegiatan dan pembuatan artikel.

\section{DAFTAR PUSTAKA}

Penulisan daftar pustaka menggunakan aplikasi manajemen referensi (seperti Mendeley, Endnote, Zotero, dll) dengan system American Psychological Association (APA) 6th edition. Hanya pustaka yang dirujuk dalam teks yang dituliskan dalam daftar pustaka. Minimal daftar pustaka 10 dengan ketentuan $80 \%$ berasal dari sumber primer. Semua referensi yang disebutkan harus ditulis berdasarkan referensi yang disusun dari A hingga $Z$.

Dalam teks

Kakao sebagai salah satu pangan fungsional di Madiun (Ariyantoro et al., 2019). Hasil penelitian Widodo et al. (2019) perlu pendekatan ramah lingkungan untuk mencegah polusi yang buruk, yang dilakukan dengan meningkatkan kesadaran masyarakat dan pelaku bisnis dalam mengelola limbah cair dengan membuat sistem pengolahan air limbah terintegrasi.

Dalam Daftar Pustaka:

Ariyantoro, A. R., Anam, C., Kawiji, K., Minardi, S., Zulfa, F., Purnomo, D., ... Widiatmoko, C. (2019). Pengembangan Produk Cokelat Couverture dengan Penambahan Pangan Fungsional di Desa Randualas Kecamatan Kare Kabupaten Madiun. PRIMA: Journal of Community Empowering and Services, 3(2), 50-55. https://doi.org/10.20961/prima.v3i2.37835

Widodo, T., Budiastuti, M. T. S., \& Komariah, K. (2019). Water Quality and Pollution Index in Grenjeng River, Boyolali Regency, Indonesia. Caraka Tani: Journal of Sustainable Agriculture, 34(2), 150-161. https://doi.org/ 10.20961/carakatani.v34i2.29186

File template dapat diunduh di situs web:

URL: $\underline{\text { http:// bit.ly/templateagrihealth }}$

\section{Surat Pernyataan dan Verifikasi Pendaftaran Naskah}

Pendaftaran sebuah naskah menyiratkan bahwa karya yang didaftarkan belum dipublikasikan sebelumnya dan tidak dalam proses untuk publikasi di tempat lain. Penulis menyetujui bahwa naskah tidak akan dipublikasikan di tempat lain dalam bentuk yang sama, dalam bahasa Inggris atau dalam bahasa lain, tanpa persetujuan tertulis dari pemegang hak cipta. 
AgriHealth: Journal of Agri-food, Nutrition and Public Health

ISSN 2722-0656 (Print)

ISSN 2722-0648 (Online)

Volume 2 Nomor 1 April 2021

Penulis harus menyerahkan "Surat Pernyataan Penulis" sebagai bahan pelengkap pada saat penyerahan naskah. Naskah tidak akan diproses apabila tanpa surat pernyataan tersebut.

\section{Mitra}

Google AagARuDA crossref âinta 
